Original article

\title{
Low tobacco-related cancer incidence in offspring of long-lived siblings: a comparison with Danish national cancer registry data
}

\author{
Jacob K. Pedersen MSc ${ }^{\mathrm{a}, *}$, Axel Skytthe PhD ${ }^{\mathrm{a}}$, Matt McGue PhD ${ }^{\mathrm{a}, \mathrm{b}}$, Lawrence S. Honig MD, PhD ${ }^{\mathrm{c}, \mathrm{d}, \mathrm{e}}$, \\ Claudio Franceschi PhD ${ }^{\text {f,g,h,i,j, Thomas B.L. Kirkwood PhD }}{ }^{\mathrm{k}}$, Giuseppe Passarino PhD ${ }^{1}$, \\ P. Eline Slagboom PhD ${ }^{\mathrm{m}, \mathrm{n}}$, James W. Vaupel PhD ${ }^{\circ}$, Kaare Christensen MD, DMSc ${ }^{\mathrm{a}, \mathrm{p}, \mathrm{q}}$
}

\footnotetext{
${ }^{a}$ The Danish Aging Research Center, Institute of Public Health, University of Southern Denmark, Odense, Denmark

${ }^{\mathrm{b}}$ Department of Psychology, University of Minnesota, Minneapolis, MN

${ }^{c}$ Gertrude H. Sergievsky Center, College of Physicians and Surgeons, Columbia University, New York, NY

${ }^{\mathrm{d}}$ Taub Institute for Research on Alzheimer's Disease and the Aging Brain, College of Physicians and Surgeons, Columbia University, New York, NY

e Department of Neurology, College of Physicians and Surgeons, Columbia University, New York, NY

f DIMES-Department of Experimental, Diagnostic and Specialty Medicine, University of Bologna, Bologna, Italy

${ }^{g}$ CIG-Interdepartmental Centre "L. Galvani” for Integrated Studies of Bioinformatics, Biophysics and Biocomplexity, University of Bologna, Bologna, Italy

${ }^{\mathrm{h}}$ IRCSS - Institute of Neurological Sciences of Bologna, Bologna, Italy

${ }^{\mathrm{i}}$ ISOF-CNR - Institute of Organic Synthesis and Photoreactivity, Bologna, Italy

${ }^{\mathrm{j}}$ IGM-CNR - Institute of Molecular Genetics, Unit of Bologna IOR, Bologna, Italy

${ }^{\mathrm{k}}$ Institute for Ageing and Health, Campus for Ageing and Vitality, Newcastle University, Newcastle, UK

${ }^{1}$ Department of Biology, Ecology and Earth Sciences, University of Calabria, Rende, Italy

${ }^{\mathrm{m}}$ Department of Molecular Epidemiology, Leiden University Medical Centre, Leiden, The Netherlands

${ }^{\mathrm{n}}$ Netherlands Consortium for Healthy Ageing, Leiden, The Netherlands

${ }^{\circ}$ MPIDR-Max Planck Institute for Demographic Research, Rostock, Germany

${ }^{\mathrm{p}}$ Department of Clinical Genetics, Odense University Hospital, University of Southern Denmark, Odense, Denmark

${ }^{\mathrm{q}}$ Department of Clinical Biochemistry and Pharmacology, Odense University Hospital, University of Southern Denmark, Odense, Denmark
}

\section{A R T I C L E I N F O}

Article history:

Received 20 September 2014

Accepted 9 March 2015

Available online 18 March 2015

\section{Keywords:}

Cancer

Familial clustering

Longevity

Cohort study

Lifestyle and aging

\begin{abstract}
A B S T R A C T
Purpose: Familial clustering of longevity is well documented and includes both genetic and other familial factors, but the specific underlying mechanisms are largely unknown. We examined whether low incidence of specific cancers is a mechanism for familial clustering of longevity.

Methods: The study population of individuals from longevity-enriched families consisted of 3267 offspring from 610 Danish long-lived families defined by two siblings attaining an age of 90 years or more. The offspring of the long-lived siblings were followed from 1968 to 2009. Using high-quality registry data, observed numbers of cancers were compared with expected numbers based on gender-, calendar period-, and age-specific incidence rates in the general population.

Results: During the 41-year-follow-up period, a total of 423 cancers occurred in 397 individuals. The standardized incidence ratios (95\% confidence interval) for offspring of long-lived individuals were $0.78(0.70-0.86)$ for overall cancer; $0.66(0.56-0.77)$ for tobacco-related cancer; $0.34(0.22-0.51)$ for lung cancer; $0.88(0.71-1.10)$ for breast cancer; $0.91(0.62-1.34)$ for colon cancer.

Conclusions: The low incidence of tobacco-related cancers in long-lived families compared with non -tobacco-related cancers suggests that health behavior plays a central role in lower early cancer incidence in offspring of long-lived siblings in Denmark.
\end{abstract}

(C) 2015 Elsevier Inc. All rights reserved.

\footnotetext{
* Corresponding author. Epidemiology, Biostatistics, and Biodemography, Institute of Public Health, University of Southern Denmark, J.B. Winsløws Vej 9B, 5000 Odense C, Denmark. Tel.: +45-6550-4735; fax: +45-6550-3682.

E-mail address: jkrabbe@health.sdu.dk (J.K. Pedersen).
}

\section{Introduction}

Familial clustering of longevity has been demonstrated in a number of studies in different populations. It has been shown that relatives of individuals or sib pairs attaining high ages have a better survival than comparison groups [1-3]; that the oldest proportion 
of a population is more closely related than would be expected by chance [4]; and that the association between long-lived probands and survival in their relatives is stronger the closer they are related $[4,5]$. Several studies of Scandinavian twins found that life span is moderately heritable [6-8], and that the heritability is likely to increase at the highest ages [9]. Less is known about the mechanisms behind the familial clustering of longevity, but both genetic and environmental factors contribute to longevity. In crosssectional studies, evidence has been provided for better health status in longevity-enriched families compared with control groups not enriched for longevity in terms of lower prevalence of myocardial infarction, hypertension, diabetes, cardiovascular disease, and pulmonary disease [10-13]. Interestingly, in a U.S. and a Danish nationwide study $[10,12]$, no association was found between familial longevity enrichment and cancer prevalence, and in a Dutch study [14], no association between number of cancerassociated risk alleles and longevity-enriched families was found. Studies involving other measures of health such as self-rated health and physical measures [12] and measures of tasks requiring attention, working memory, and semantic processing [15] found favorable outcomes in offspring of longevity-enriched families when compared with individuals without a family history of exceptional survival.

To better understand the mechanisms that lead to these states of good health in long-lived families and to longevity itself, longitudinal studies are needed that follow members of these families over time. Some such studies exist and have found lower cause-specific mortality and delayed onset of disease for several leading causes of death [16-19], but only one [18] found lower cancer mortality. The previously mentioned literature provides mixed evidence for a lower cancer occurrence as a mechanism for clustering of longevity in families. Although some animal studies indicate a trade-off mechanism between aging and the risk of cancer [20-24], two more recent studies suggest that familial longevity enrichment is associated with lower cancer incidence $[25,26]$. In the following, we take advantage of Danish population registers, and the screening of long-lived families in three nationwide studies to shed light on possible mechanisms by comparing incidence of all cancers except nonmelanoma skin cancer, as well as incidence of specific common cancer types, breast cancer, colon cancer, prostate cancer, lung cancer, and tobacco-related cancer, in the long-lived families, with population-based cancer incidence rates stratified for gender, age, and calendar period. The offspring generation of long-lived families is thus compared to the entire Danish population using the population-based rates. Based on the Danish twin study [25], we expect to find lower cancer incidence among offspring, indicating that lower cancer occurrence is contributing to familial longevity. Also, incidence of specific cancers may provide further information about the mechanism.

\section{Methods}

\section{Study population}

For a more detailed description of the procedure for identifying and including offspring from long-lived families, see Appendix. Here, follows a brief outline of the inclusion procedure: The identification of offspring from long-lived families was undertaken in three nationwide, consecutive studies in Denmark, for which recruitment ran sequentially during the years 2004 to 2009, a pilot study-Danish Oldest Siblings (DOS) pilot study, the Genetics of Healthy Aging (GeHA) study [27], and the Long Life Family Study (LLFS) [28].

Initially, all individuals born before April 2, 1918, and alive in 2004 were identified in the Danish Civil Registration System
(DCRS), which covers all persons alive and living in Denmark on or after April 2, 1968 [29]. Identification of long-lived sib pairs from the DCRS and church records is described in the Appendix. In all, 1511 siblings from 659 families were enrolled in either DOS, GeHA or LLFS, with 246 siblings from 114 families in DOS, 1000 siblings from 469 families in GeHA, and 265 siblings from 76 families in LLFS. To further ensure reliable family information and that the families in this study were strongly enriched for longevity, we restricted our study population to the offspring of those siblings who (1) participated in an interview in either DOS, GEHA or LLFS, (2) survived to the age of 90 years or more before July 1, 2010, and (3) had at least another participating sibling surviving to the age of 90 years or more before July 1,2010 . This means that the population under study consisted of the offspring of those sets of siblings who survived to the age of 90 years or more and participated in an interview (DOS, GEHA, or LLFS). A total of 1405 siblings from 628 families (99 families in the DOS, 454 families in the GeHA study, and 75 families in the LLFS) fulfilled these criteria. Of the 1405 siblings, 264 had no offspring, so of the remaining 1141 siblings from 611 families, 3297 offspring were identified. Of these offspring, six had unknown vital status in the DCRS, further 17 had a status as emigrants at the end of study in 2009 but with an unknown date of emigration, and one with emigration status had emigrated before April 2, 1968; four offspring had died at an unknown date, and two had died before April 2, 1968. The remaining 3267 offspring from 610 families comprise our study population.

\section{Cancer incidence}

To study cancer incidence in the long-lived families, we used the personal identification number to link the study population to the Danish Cancer Registry (DCR) [30]. This registry is populationbased and contains records of all incidences of malignant neoplasms in the Danish population from 1943 onward. The register is considered almost complete: in a comparison with independent and redundant data from the Hospital Discharge Registry system, death certificates, and a pathology register, the validity and completeness of the DCR was found to be 95\% to 98\% [30-32]. Moreover, with a proportion of $89 \%$ of all tumors having been morphologically verified, it has a high degree of validity.

The classification of cancer in the DCR before 1977 was based on the modified International Classification of Diseases (ICD) seventh revision classification, between 1978 and 2003 cancer was also classified according to the ICD-Oncology-1 (ICD-O-1) classification, and from 2004 onward, the ICD-10 and ICD-O-3 classifications have both been used. Furthermore, for the period 1978 to 2003, the classification was converted from modified ICD-7 to ICD-10 and from ICD-O-1 to ICD-O-3 [30]. To allow for comparison of cancer incidence across periods of different classification systems, cancer diagnoses were grouped into 41 entities of specific cancers following the methodology in the trans-Nordic cancer study collaboration (NORDCAN) [33,34]. We studied overall incidence as well as breast, colon, prostate, lung, and combined tobacco-related cancer. In the study of all cancers, we excluded nonmelanoma skin cancer, and in the study of overall as well as tobacco-related cancer, we permitted an individual to have several primary cancers while adhering to the International Agency for Research on Cancer or the International Association of Cancer Registries rules of counting multiple cancers in the same site as one primary cancer only [35]. Consequently, prevalent cases do not contribute with new cancers to the cancer site for which they are prevalent, nor do they contribute with risk time for the cancer incidence of that specific site. The category of tobacco-related cancers consisted of the pooling of the following 18 NORDCAN cancer sites (using NORDCAN terminology): lip, tongue, mouth, salivary glands, pharynx, 


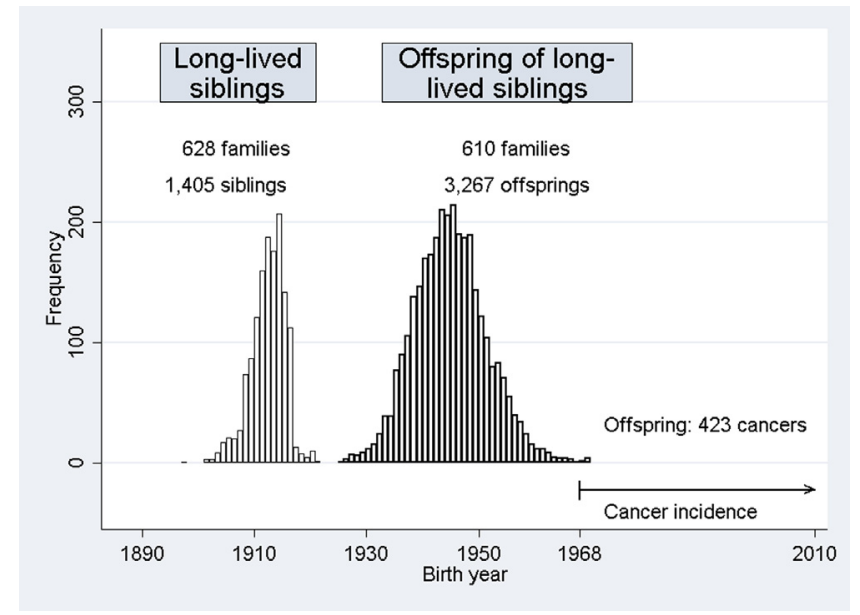

Fig. 1. Danish long-lived siblings and their offspring: birth year distribution and cancer occurrence in offspring.

esophagus, stomach, colon, rectum and anus, pancreas, nose and sinuses, larynx, lung, cervix uteri, ovary and others, kidney, bladder and others, and acute leukemia [36]. The exact ICD-10 and ICD-7 codes for the NORDCAN cancer sites have been published in Acta Oncologica (Table 2) [34].

\section{Statistical methods}

Comparison of cancer incidence between the offspring of longlived families and the background Danish population was carried out using indirect standardized incidence ratios (SIRs) stratified on 5-year age bands, 5-year calendar periods, and sex. Because members of long-lived families were linked to the DCR by their personal identification number from the DCRS, which has only been given to persons alive and living in Denmark on or after April 2, 1968, we only considered cancer incidence after this date. Last follow-up date was December 31, 2009. Estimation of SIRs was done using Poisson regression with robust standard error estimates $[37,38]$ to adjust for the family clusters.

The study has been approved by the Regional Scientific Ethical Committees for Southern Denmark (S-VF-20030227) and the Danish Data Protection Agency (\#J.nr. 2008-41-1753).

\section{Results}

A total of 3267 offspring from 610 families with 3696 identified siblings constituted the risk population of which 1641 (50.2\%) were males. The total observation time was more than 130,000 personyears. For breast cancer in women, the observation time was 64,980 person-years, and for prostate cancer in men, the observation time was 65,876 person-years.

The birth year ranged from 1921 to 1970 with a median birth year of 1944 (see Fig. 1). The median age at entry was 23.4 years (range: 0-46.6 years), and the median age at exit from study was 64.4 (range: $18.0-88.3$ years). On December 31, 2009, at the end of study, $88.9 \%$ of the initial study population of 3267 individuals was still under observation, 9.1\% were deceased, and $2.0 \%$ had outmigrated. With regard to observation time, $85.9 \%$ was in the age group 15 to 59 years, and only $13.1 \%$ was in the age group above 60 years (Tables 1 and 2). A total of 423 primary cancers were observed among 397 individuals during the study period. This corresponded to 373 individuals with one primary cancer, 22 individuals with two primary cancers, and two individuals with three primary cancers. Of these cancers, 219 (51.8\%) were diagnosed at ages 15 to 59 years, another 160 cases (37.8\%) at ages 60 to 69 years, and finally 44 cases (10.4\%) after the age of 70 years (Tables 1 and 2 ).

Table 1

Cancer incidence in offspring of Danish long-lived families from 1968 to 2009 stratified on sex and age

\begin{tabular}{|c|c|c|c|c|c|c|c|c|}
\hline \multirow[t]{2}{*}{ Sex } & \multirow[t]{2}{*}{ Age band (y) } & \multicolumn{2}{|l|}{ Risk time } & \multicolumn{2}{|c|}{$\begin{array}{l}\text { Observed number } \\
\text { of cancers }\end{array}$} & \multirow[t]{2}{*}{$\begin{array}{l}\text { Expected number } \\
\text { of cancers }\end{array}$} & \multirow[t]{2}{*}{$\begin{array}{l}\text { SIR } \\
\text { (obs/exp) }\end{array}$} & \multirow[t]{2}{*}{$95 \% \mathrm{CI}$} \\
\hline & & Person-years & $\%$ & Count & $\%$ & & & \\
\hline \multirow[t]{14}{*}{ Males } & $0-14$ & 630.3 & 1.0 & 0 & 0.0 & 0.1 & 0 & - \\
\hline & $15-29$ & $11,073.8$ & 16.8 & 3 & 1.7 & 3.6 & 0.83 & $0.27-2.54$ \\
\hline & $30-34$ & 7495.5 & 11.3 & 3 & 1.7 & 4.2 & 0.71 & $0.23-2.20$ \\
\hline & $35-39$ & 7930.2 & 12.0 & 5 & 2.9 & 6.5 & 0.77 & $0.32-1.84$ \\
\hline & $40-44$ & 7957.1 & 12.0 & 5 & 2.9 & 10.1 & 0.49 & $0.21-1.18$ \\
\hline & $45-49$ & 7876.2 & 11.9 & 9 & 5.1 & 17.5 & 0.52 & $0.27-0.98$ \\
\hline & $50-54$ & 7589.4 & 11.5 & 14 & 8.0 & 30.1 & 0.46 & $0.28-0.78$ \\
\hline & $55-59$ & 6795.0 & 10.3 & 34 & 19.4 & 47.5 & 0.72 & $0.51-1.01$ \\
\hline & $60-64$ & 5079.2 & 7.7 & 49 & 28.0 & 61.2 & 0.80 & $0.60-1.07$ \\
\hline & $65-69$ & 2607.3 & 3.9 & 34 & 19.4 & 49.2 & 0.69 & $0.49-0.98$ \\
\hline & $70-74$ & 818.6 & 1.2 & 15 & 8.6 & 21.4 & 0.70 & $0.41-1.20$ \\
\hline & $75-79$ & 171.3 & 0.3 & 4 & 2.3 & 5.3 & 0.75 & $0.24-2.39$ \\
\hline & $\geq 80$ & 28.0 & 0.0 & 0 & 0.0 & 0.9 & 0 & - \\
\hline & Total & $66,051.8$ & 100.0 & 175 & 100.0 & 257.7 & 0.68 & $0.58-0.79$ \\
\hline \multirow[t]{14}{*}{ Females } & $0-14$ & 654.4 & 1.0 & 0 & 0.0 & 0.1 & 0 & - \\
\hline & $15-29$ & $11,155.2$ & 17.0 & 3 & 1.2 & 3.6 & 0.84 & $0.27-2.60$ \\
\hline & $30-34$ & 7467.4 & 11.4 & 6 & 2.4 & 6.4 & 0.94 & $0.43-2.08$ \\
\hline & $35-39$ & 7924.2 & 12.1 & 9 & 3.6 & 12.2 & 0.74 & $0.36-1.51$ \\
\hline & $40-44$ & 7945.1 & 12.1 & 12 & 4.8 & 20.9 & 0.57 & $0.31-1.05$ \\
\hline & $45-49$ & 7804.9 & 11.9 & 24 & 9.7 & 32.7 & 0.73 & $0.50-1.08$ \\
\hline & $50-54$ & 7504.6 & 11.4 & 41 & 16.5 & 44.6 & 0.92 & $0.66-1.28$ \\
\hline & $55-59$ & 6647.7 & 10.1 & 51 & 20.6 & 54.8 & 0.93 & $0.71-1.22$ \\
\hline & $60-64$ & 4913.7 & 7.5 & 47 & 19.0 & 56.0 & 0.84 & $0.63-1.12$ \\
\hline & $65-69$ & 2598.4 & 4.0 & 30 & 12.1 & 38.3 & 0.78 & $0.55-1.12$ \\
\hline & $70-74$ & 871.8 & 1.3 & 24 & 9.7 & 15.2 & 1.58 & $1.05-2.40$ \\
\hline & $75-79$ & 141.8 & 0.2 & 1 & 0.4 & 2.9 & 0.34 & $0.05-2.46$ \\
\hline & $\geq 80$ & 14.9 & 0.0 & 0 & 0.0 & 0.3 & 0 & - \\
\hline & Total & $65,644.2$ & 100.0 & 248 & 100.0 & 288.0 & 0.86 & $0.75-0.98$ \\
\hline
\end{tabular}

Exp = expected number of cancers; obs = observed number of cancers. 
Table 2

Cancer incidence in offspring of Danish long-lived families from 1968 to 2009, male and female combined, stratified on age

\begin{tabular}{|c|c|c|c|c|c|c|c|}
\hline \multirow[t]{2}{*}{$\begin{array}{l}\text { Age } \\
\text { band }(y)\end{array}$} & \multicolumn{2}{|l|}{ Risk time } & \multicolumn{2}{|c|}{$\begin{array}{l}\text { Observed no. } \\
\text { of cancers }\end{array}$} & \multirow{2}{*}{$\begin{array}{l}\text { Expected } \\
\text { no. of } \\
\text { cancers }\end{array}$} & \multirow[t]{2}{*}{$\begin{array}{l}\text { SIR } \\
\text { (obs/exp) }\end{array}$} & \multirow[t]{2}{*}{$95 \% \mathrm{CI}$} \\
\hline & Person-years & $\%$ & Count & $\%$ & & & \\
\hline $0-14$ & 1284.7 & 1.0 & 0 & 0.0 & 0.1 & 0 & - \\
\hline $15-29$ & $22,229.0$ & 16.9 & 6 & 1.4 & 7.2 & 0.83 & $0.37-1.85$ \\
\hline $30-34$ & $14,962.9$ & 11.4 & 9 & 2.1 & 10.6 & 0.85 & $0.44-1.62$ \\
\hline $35-39$ & $15,854.5$ & 12.0 & 14 & 3.3 & 18.7 & 0.75 & $0.43-1.31$ \\
\hline $40-44$ & $15,902.2$ & 12.1 & 17 & 4.0 & 31.1 & 0.55 & $0.33-0.90$ \\
\hline $45-49$ & $15,681.1$ & 11.9 & 33 & 7.8 & 50.2 & 0.66 & $0.47-0.91$ \\
\hline $50-54$ & $15,094.0$ & 11.5 & 55 & 13.0 & 74.8 & 0.74 & $0.55-0.98$ \\
\hline $55-59$ & $13,442.7$ & 10.2 & 85 & 20.1 & 102.3 & 0.83 & $0.67-1.03$ \\
\hline $60-64$ & 9992.8 & 7.6 & 96 & 22.7 & 117.1 & 0.82 & $0.66-1.02$ \\
\hline $65-69$ & 5205.8 & 4.0 & 64 & 15.1 & 87.5 & 0.73 & $0.57-0.94$ \\
\hline $70-74$ & 1690.4 & 1.3 & 39 & 9.2 & 36.6 & 1.07 & $0.77-1.49$ \\
\hline $75-79$ & 313.1 & 0.2 & 5 & 1.2 & 8.2 & 0.61 & $0.22-1.65$ \\
\hline$\geq 80$ & 42.9 & 0.0 & 0 & 0.0 & 1.2 & 0 & - \\
\hline Total & $131,696.0$ & 100.0 & 423 & 100.0 & 545.7 & 0.78 & $0.70-0.86$ \\
\hline
\end{tabular}

Exp $=$ expected number of cancers; obs $=$ observed number of cancers.

The comparison of overall cancer incidence between the offspring and the Danish population is found in Tables 1 and 2 together with age-specific SIRs. We found 22\% fewer cancer cases among the offspring compared with the Danish population, corresponding to 423 observed versus 545.7 expected cancer cases. The SIR was 0.68 (95\% confidence interval [CI]: 0.58-0.79) for men and 0.86 (95\% CI: 0.75-0.98) for women. For men, at ages under 29 years, more than 80 years, and in intervening 5-year age groups, age-specific SIRs varied between 0.46 and 0.83 . Similarly for women, in the same age intervals, the SIRs ranged between 0.57 and 0.94 with two exceptions, one at ages 70 to 74 years for which the SIR was 1.58 (95\% CI: $1.05-2.40)$ and the other at ages 75 to 79 years with a SIR of 0.34 (95\% CI: 0.05-2.46).

In the analyses of specific cancer types (Table 3), without correcting the significance level for multiple testing, we found a markedly and significantly lower incidence of lung cancer in the

Table 3

Cancer incidence of overall and specific cancers in offspring of Danish long-lived families from 1968 to 2009, stratified on sex

\begin{tabular}{|c|c|c|c|c|}
\hline Cancer type & $\begin{array}{l}\text { Observed } \\
\text { no. of } \\
\text { cancers }\end{array}$ & $\begin{array}{l}\text { Expected } \\
\text { no. of } \\
\text { cancers }\end{array}$ & $\begin{array}{l}\text { SIR } \\
\text { (obs/exp) }\end{array}$ & $95 \% \mathrm{CI}$ \\
\hline \multicolumn{5}{|l|}{ Overall } \\
\hline Males & 175 & 257.7 & 0.68 & $0.58-0.79$ \\
\hline Females & 248 & 288.0 & 0.86 & $0.75-0.98$ \\
\hline Males + females & 423 & 545.7 & 0.78 & $0.70-0.86$ \\
\hline \multicolumn{5}{|l|}{ Breast } \\
\hline Females & 84 & 95.2 & 0.88 & $0.71-1.10$ \\
\hline \multicolumn{5}{|l|}{ Colon } \\
\hline Males & 12 & 17.9 & 0.67 & $0.38-1.17$ \\
\hline Females & 19 & 16.2 & 1.17 & $0.71-1.94$ \\
\hline Males + females & 31 & 34.1 & 0.91 & $0.62-1.34$ \\
\hline \multicolumn{5}{|l|}{ Prostate } \\
\hline Males & 43 & 38.2 & 1.13 & $0.84-1.52$ \\
\hline \multicolumn{5}{|l|}{ Lung } \\
\hline Males & 8 & 39.5 & 0.20 & $0.10-0.40$ \\
\hline Females & 16 & 31.7 & 0.50 & $0.30-0.84$ \\
\hline Males + females & 24 & 71.2 & 0.34 & $0.22-0.51$ \\
\hline \multicolumn{5}{|c|}{ Tobacco-related cancer (including lung) } \\
\hline Males & 76 & 143.4 & 0.53 & $0.43-0.66$ \\
\hline Females & 96 & 117.3 & 0.82 & $0.66-1.02$ \\
\hline Males + females & 172 & 260.7 & 0.66 & $0.56-0.77$ \\
\hline \multicolumn{5}{|c|}{ Tobacco-unrelated cancer } \\
\hline Males & 99 & 114.3 & 0.87 & $0.71-1.06$ \\
\hline Females & 152 & 170.6 & 0.89 & $0.75-1.05$ \\
\hline Males + females & 251 & 284.9 & 0.88 & $0.77-1.00$ \\
\hline
\end{tabular}

Exp $=$ expected number of cancers; obs $=$ observed number of cancers. offspring for both sexes. The SIR estimate was 0.20 (95\% CI: $0.10-0.40$ ) for men and 0.50 (95\% CI: $0.30-0.84)$ for women. Similarly, for tobacco-related cancer (including lung cancer) the SIR was 0.53 (95\% CI: 0.43-0.66) for men and 0.82 (95\% CI: 0.66-1.02) for women. For tobacco-related cancer, we observed 172 cancers which compares to an expected number of 260.7 and a difference of 88.7 cancers. This leaves 33.9 fewer cases of tobacco-unrelated cancer among offspring when comparing the observed 251 tobacco-unrelated cancers with an expected number of 284.9 tobacco-unrelated cancers in a Danish population with similar sex, age, and birth year distribution, corresponding to a SIR of 0.88 (95\% CI: 0.77-1.00). Considering even tobacco-related cancers excluding lung cancer, we observed 148 cases compared with an expected 189.4 cases corresponding to a SIR of 0.78 (95\% CI: $0.66-0.93$ ).

Generally, the observed SIRs were lower in males than in females, most pronounced for tobacco-related cancers: $0.53(0.43-0.66)$ versus $0.82(0.66-1.02)$. Of the 88.7 "missing" tobacco-related cancers among the longevity-enriched offspring, males accounted for $67.4(76 \%)$.

In these results, multiple testing problems may be an issue, and a conservative way to adjust for this is to use a Bonferroni correction. Basing the correction on 12 individual hypotheses, the SIRs for overall cancer and lung cancer were no longer significantly below 1 among females, but among males the SIRs for overall cancer, lung cancer, and tobacco-related cancer remained significantly well below 1 .

In our analyses, we have excluded 17 emigrants with unknown date of migration, six individuals with unknown vital status, and four individuals with unknown date of death. Because of the access of all Danish citizens to a high-quality, free health care system and, given the recruitment of the study, to the presumably Danish family network of the offspring, it is unlikely that migrants should have higher cancer incidence than other offspring. However, a possible bias toward too low SIR estimates as a consequence of the exclusion cannot be ruled out. To assess an upper bound of the possible impact this exclusion could have on biasing our SIR estimates, we performed a sensitivity analysis for the overall cancer SIRs, specifying that all 27 individuals had cancer, uniformly diagnosed over the study period and with subsequent death 7 days after cancer diagnosis. As expected, the SIRs of the sensitivity analysis were slightly larger than those from our main analysis: 0.73 (95\% CI: $0.63-0.85$ ) for males and 0.90 (95\% CI: 0.79-1.03) for females.

The reduced occurrence of tobacco-related cancer prompted an analysis of the smoking behavior in the offspring of the families from the LLFS, because for these families questionnaire data on smoking habits in offspring were available. Among 627 interviewed offspring in LLFS, 19.1\% (95\% CI: 15.7-23.1) were current smokers and $9.6 \%$ (95\% CI: 7.3-12.6) were current heavy smokers. These prevalences were $24 \%$, respectively, $17 \%$ lower on a relative scale than predicted from age- and sex-specific smoking prevalences in the Danish population (www.sundhedsprofil2010.dk).

\section{Discussion}

Our findings of lower cancer occurrence in the offspring of longlived individuals confirm the findings of a Danish twin study [25] that indicates that longer life span of one co-twin is associated with lower cancer incidence in the other. Also, our findings are in agreement with those of the Health and Retirement Study cohort [26], which is a U.S. representative cohort study that showed that having one or two long-lived parents is associated with lower cancer incidence compared with having two parents attaining an intermediate age. The novelty of the finding in our study is that the lower cancer incidence in long-lived families can largely be 
attributed to lower tobacco-related cancer incidence. Two factors might underlie our finding of reduced tobacco-related cancers in individuals with long-lived parents. First, genetic factors contributing to longevity might overlap genes that protect the host from developing cancer, given exposure. Second, genetic factors contributing to longevity might overlap genes related to smoking exposure.

Scandinavian twin studies have estimated that $20 \%$ to $30 \%$ of the variation in life span can be attributed to genetic factors, and that this heritability increases with age, whereas essentially no effect of shared environment has been found. At a first glance, a finding of familial clustering of low smoking prevalence could be seen as a contradiction to twin studies that have not been able to demonstrate an effect of shared familial environment as a mechanism for familial clustering of longevity [6-9]. However, it is quite possible that genes contributing to longevity express themselves through an affinity for healthy lifestyles: For example, lifestyles in midlife and late life, such as smoking and physical activities, have a small to moderate degree of heritability [39]. The choice of lifestyles is a decision of the individual that may be influenced by genetically heritable personality traits and abilities, so that, for instance, physically adept individuals seek out environments with a high degree of physical activity. The lower tobacco-related cancer incidence in offspring of long-lived siblings may be explained by genetic loci in the genome of the longevity families contributing to longevity by protecting smokers from developing cancer. Alternatively, the families may display beneficial smoking habits because of the influence of such loci or shared environmental factors. The latter explanation seems most likely considering the lower smoking frequency found among the offspring in the LLFS.

The overall cancer SIR of 0.75 in our study was remarkably similar to the hazard ratio estimate of 0.76 for cancer incidence in the Health and Retirement Study [26] that compared offspring having at least one long-lived parent to those having two intermediate-lived parents, and where the offspring were followed from about 55 to 75 years of age. The hazard ratio estimate was, however, adjusted for environmental factors, including smoking, but this only minimally modified the unadjusted hazard ratio. To the extent that familial longevity is associated with less smoking, it seems reasonable to expect that cancer-specific mortality should be lower in longevity-enriched families, as was found in the New England Centenarian Study [18] but not in the Utah Population Database study [17]. In the former study, the centenarian offspring had lower smoking prevalence than the controls, whereas in the latter study of a Utah population, no information on smoking habits was presented. However, Utah has one of the lowest smoking prevalences in the U.S., so longevity-enriched families in Utah are perhaps not discriminated by their smoking habits. Moreover, in the Utah study, the main analysis was adjusted for a family history of cancer, and without adjustment there was in fact a moderately lower cancer mortality associated with familial longevity.

Of the specific cancer types, lung cancer stood out as having a very low incidence in the offspring, which, given the strong association between smoking and lung cancer, further supports the finding that smoking prevalence contributes to familial clustering of longevity. Also, we found lower SIRs for males than females, most pronounced for tobacco-related cancers, so lower smoking prevalence among the offspring, and in particular the male offspring, is likely to be the major factor resulting in the low cancer incidence. Solid organ cancers such as breast, colon, or prostate cancer did not show marked incidence differences between the offspring and the Danish population, although an observed SIR for breast cancer below 1 was slightly opposite of what would be expected if longevity-enriched families were associated with a higher socioeconomic status, as a lower smoking prevalence could suggest.
The strength in this study lies in the large number of individuals from longevity-enriched families (close to 3300) and the comparison group of the entire Danish population (about 5 million), both groups followed for more than four decades. The comparison ensures that the association between the groups and cancer incidence is not partially due to higher than normal incidence in the group not enriched for longevity, as might be the case if offspring of short-lived parents were selected as comparison group. Moreover, the highquality registry data on demographic and cancer variables have ensured the virtually complete information on ages and cancer incidence with no loss to follow-up before death or end of study, except for $2 \%$ of out-migrants, and they allowed for adjustment for age, calendar period, and sex. Also, the initiation of the DCR in 1943 has meant that probably no prevalent cancer cases are registered as incident cases after 1968, as they would otherwise have remained undetected for more than 25 years. A weakness of our study is the unavailability of response rates in the recruitment of nonagenarian siblings, which makes it difficult to assess the possible extent of a response bias, for example, a tendency to recruit siblings with safer behavior than other long-lived siblings and potentially with safer health behaviors in the next generation. Another weakness is that the observational power is rather small after the age of 70 years. Hence, the association of familial longevity with, for example, prostate cancer incidence could not be fully tested in the present sample.

\section{Conclusion}

This study suggests lower tobacco-related cancer incidence as a contributing mechanism for lower early cancer incidence in offspring of long-lived siblings.

\section{Acknowledgment}

This work is supported by the Danish Agency for Science, Technology and Innovation/The Danish Council for Independent Research (grant number 11-107308) and by the National Institute on Aging (grant number P01 AG08761). The LLFS study is funded by the U.S. National Institute on Aging, National Institutes of Health (NIA/NIH cooperative agreements U01AG023712, U01AG23744, U01AG023746, U01AG023749, U01AG023755). The work is based on the EU GEHA (Genetics of Healthy Aging) Project (contract number LSHM-CT-2004-503-270) and the Odense University Hospital AgeCare program (Academy of Geriatric Cancer Research). The Danish Aging Research Center is supported by a grant from the VELUX Foundation (grant number: Velux 31205).

\section{References}

[1] Perls TT, Bubrick E, Wager CG, Vijg J, Kruglyak L. Siblings of centenarians live longer. Lancet 1998;351(9115):1560.

[2] Schoenmaker M, de Craen AJ, de Meijer PH, Beekman M, Blauw GJ, Slagboom PE, et al. Evidence of genetic enrichment for exceptional survival using a family approach: the Leiden Longevity Study. Eur J Hum Genet 2006;14(1):79-84.

[3] Willcox BJ, Willcox DC, He Q, Curb JD, Suzuki M. Siblings of Okinawan centenarians share lifelong mortality advantages. J Gerontol A Biol Sci Med Sci 2006;61(4):345-54.

[4] Gudmundsson H, Gudbjartsson DF, Frigge M, Gulcher JR, Stefansson K. Inheritance of human longevity in Iceland. Eur J Hum Genet 2000;8(10):743-9.

[5] Kerber RA, O’Brien E, Smith KR, Cawthon RM. Familial excess longevity in Utah genealogies. J Gerontol A Biol Sci Med Sci 2001;56(3):B130-9.

[6] Herskind AM, McGue M, Holm NV, Sorensen TI, Harvald B, Vaupel JW. The heritability of human longevity: a population-based study of 2872 Danish twin pairs born 1870-1900. Hum Genet 1996;97(3):319-23.

[7] Ljungquist B, Berg S, Lanke J, McClearn GE, Pedersen NL. The effect of genetic factors for longevity: a comparison of identical and fraternal twins in the Swedish Twin Registry. J Gerontol Ser A Biol Sci Med Sci 1998;53(6):M441-6.

[8] Skytthe A, Pedersen NL, Kaprio J, Stazi MA, Hjelmborg JV, Iachine I, et al. Longevity studies in GenomEUtwin. Twin Res 2003;6(5):448-54. 
[9] Hjelmborg Jv, Iachine I, Skytthe A, Vaupel JW, McGue M, Koskenvuo M, et al. Genetic influence on human lifespan and longevity. Hum Genet 2006;119(3):312-21.

[10] Terry DF, Wilcox M, McCormick MA, Lawler E, Perls TT. Cardiovascular advantages among the offspring of centenarians. J Gerontol Ser A Biol Sci Med Sci 2003;58(5):M425-31.

[11] Westendorp RG, van Heemst D, Rozing MP, Frolich M, Mooijaart SP, Blauw GJ, et al. Nonagenarian siblings and their offspring display lower risk of mortality and morbidity than sporadic nonagenarians: the Leiden Longevity Study. J Am Geriatr Soc 2009;57(9):1634-7.

[12] Frederiksen H, McGue M, Jeune B, Gaist D, Nybo H, Skytthe A, et al. Do children of long-lived parents age more successfully? Epidemiology 2002;13(3):334-9.

[13] Newman AB, Glynn NW, Taylor CA, Sebastiani P, Perls TT, Mayeux R, et al. Health and function of participants in the Long Life Family Study: a comparison with other cohorts. Aging 2011;3(1):63-76.

[14] Beekman M, Nederstigt C, Suchiman HE, Kremer D, van der Breggen R, Lakenberg N, et al. Genome-wide association study (GWAS)-identified disease risk alleles do not compromise human longevity. Proc Natl Acad Sci U S A 2010;107(42):18046-9.

[15] Barral S, Cosentino S, Costa R, Matteini A, Christensen K, Andersen SL, et al. Cognitive function in families with exceptional survival. Neurobiol Aging 2012;33(3):619.e1-7.

[16] Florez H, Ma Y, Crandall JP, Perreault L, Marcovina SM, Bray GA, et al. Parental longevity and diabetes risk in the Diabetes Prevention Program. J Gerontol Ser A Biol Sci Med Sci 2011;66(11):1211-7.

[17] O'Brien E, Kerber R, Smith K, Mineau G, Boucher K, Reed DL. Familial mortality in the Utah population database: characterizing a human aging phenotype. J Gerontol Ser A Biol Sci Med Sci 2007;62(8):803-12.

[18] Terry DF, Wilcox MA, McCormick MA, Pennington JY, Schoenhofen EA, Andersen SL, et al. Lower all-cause, cardiovascular, and cancer mortality in centenarians' offspring. J Am Geriatr Soc 2004;52(12):2074-6.

[19] Terry DF, Wilcox MA, McCormick MA, Perls TT. Cardiovascular disease delay in centenarian offspring. J Gerontol Ser A Biol Sci Med Sci 2004;59(4):385-9.

[20] Campisi J. Cancer and ageing: rival demons? Nat Rev Cancer 2003;3(5):339-49.

[21] Campisi J. Aging and cancer cell biology, 2008. Aging Cell 2008;7(3):281-4.

[22] Ukraintseva SV, Arbeev KG, Akushevich I, Kulminski A, Arbeeva L, Culminskaya I, et al. Trade-offs between cancer and other diseases: do they exist and influence longevity? Rejuvenation Res 2010;13(4):387-96.

[23] Weinstein BS, Ciszek D. The reserve-capacity hypothesis: evolutionary origins and modern implications of the trade-off between tumor-suppression and tissue-repair. Exp Gerontol 2002;37(5):615-27.

[24] Yashin AI, Ukraintseva SV, Akushevich IV, Arbeev KG, Kulminski A, Akushevich L. Trade-off between cancer and aging: what role do other diseases play? Evidence from experimental and human population studies. Mech Ageing Dev 2009;130(1-2):98-104.
[25] Christensen K, Pedersen JK, Hjelmborg JV, Vaupel JW, Stevnsner T, Holm NV, et al. Cancer and longevity - is there a trade-off? A study of cooccurrence in Danish twin pairs born 1900-1918. J Gerontol Ser A Biol Sci Med Sci 2012;67(5):489-94.

[26] Dutta A, Henley W, Robine JM, Langa KM, Wallace RB, Melzer D. Longer lived parents: protective associations with cancer incidence and overall mortality. J Gerontol Ser A Biol Sci Med Sci 2013;68(11):1409-18.

[27] Skytthe A, Valensin S, Jeune B, Cevenini E, Balard F, Beekman M, et al. Design, recruitment, logistics, and data management of the GEHA (Genetics of Healthy Ageing) project. Exp Gerontol 2011;46(11):934-45.

[28] Sebastiani P, Hadley EC, Province M, Christensen K, Rossi W, Perls TT, et al. A family longevity selection score: ranking sibships by their longevity, size, and availability for study. Am J Epidemiol 2009;170(12):1555-62.

[29] Pedersen CB. The Danish Civil Registration System. Scand J Public Health 2011;39(Suppl 7):22-5.

[30] Gjerstorff ML. The Danish Cancer Registry. Scand J Public Health 2011;39(Suppl 7):42-5.

[31] Østerlind A, Jensen OM. Evaluering af cancerregistreringen i Danmark 1977: en præliminær evaluering af Cancerregistrets og Landspatientregistrets registrering af cancertilfælde. Ugeskr Læger 1985;147:2483-8.

[32] Storm HH, Michelsen EV, Clemmensen IH, Pihl J. The Danish Cancer Registry-history, content, quality and use. Danish Med Bull 1997; 44(5):535-9.

[33] Engholm G, Storm HH, Ferlay J, Christensen N, the Nordic Cancer Registries, on behalf of the Association of Nordic Cancer Registries (ANCR). NORDCAN. 2012 [updated December]. Available from: http://www-dep.iarc.fr/nordcan.htm. Accessed April 10, 2013.

[34] Engholm G, Ferlay J, Christensen N, Bray F, Gjerstorff ML, Klint A, et al NORDCAN-a Nordic tool for cancer information, planning, quality control and research. Acta Oncol 2010;49(5):725-36.

[35] International Association of Cancer Registries, International Agency for Research on Cancer, European Network of Cancer Registries. International rules for multiple primary cancers (ICD-O third edition). Lyon: IARC; 2004. Internal Report No. 2004/2.

[36] American Cancer Society. Cancer facts \& figures, 2013. 2013. Available from: http://www.cancer.org/acs/groups/content/@epidemiologysurveilance/ documents/document/acspc-036845.pdf. Accessed August 20, 2013.

[37] White H. A heteroskedasticity-consistent covariance matrix estimator and a direct test for heteroskedasticity. Econometrika 1980;48:817-38.

[38] Huber PJ. The behavior of maximum likelihood estimates under nonstandard conditions. In Proceedings of the Fifth Berkeley Symposium on Mathematical Statistics and Probability. 1967;1:221-223.

[39] McGue M, Skytthe A, Christensen K. The nature of behavioural correlates of healthy ageing: a twin study of lifestyle in mid to late life. Int J Epidemiol 2014;43(3):775-82. 


\section{Appendix}

\section{The study population}

The identification of long-lived families in Denmark was undertaken systematically in five steps. Initially, all individuals born before April 2, 1918, and alive in 2004 were identified in the Danish Civil Registration System (DCRS), which covers all persons alive and living in Denmark on or after April 2, 1968 [1]. Among other variables, this registry includes information on personal identification number, gender, date and place of birth, continuously updated vital status, and the identity of parents and spouses; the latter, although, only systematically from 1968 . After matching the individuals identified in step 1 in clusters of individuals with the same birth parish and surname, the second step consisted of selecting male-male pairs, female-female pairs and male-female pairs from each cluster of matched individuals. When a cluster consisted of more than two persons of the relevant sex combination, the oldest two individuals in the cluster were chosen. The third step was to identify which of these potential pairs of siblings were actual siblings by tracing the names of their parents in church records from each birth parish. This resulted in the identification of 3636 families with at least two siblings being alive and having reached the age of 86 years or more. As the fourth step, siblings were invited to participate in one of three studies at the Epidemiology unit of the University of Southern Denmark, for which recruitment ran sequentially in the following order: the Danish Oldest Siblings (DOS) pilot study, the Genetics of Healthy Aging (GeHA) study [2], and the Long Life Family (LLFS) study [3]. Priority was given to inviting the oldest pairs and then to brothers.
Recruitment to DOS was conditional on both siblings being alive and 88 years or older; recruitment to GeHA required both siblings to be alive and above the age of 90 years, and the LLFS recruited only families with a family longevity selection score above 7 [3] Although higher family longevity selection scores are closely (positively) correlated with exceptional longevity in families, they also correlate with the families being large and having many living members at high ages at the time of recruitment. A family could only be in one of the following three studies: DOS, GeHA, or LLFS. Recruitment in the GeHA study led to subsequent exclusion from recruitment in the LLFS. Finally, as the fifth step, siblings from sibships with at least two siblings alive and willing to participate were enrolled in the respective studies until the target number of families was reached. This resulted in a total of 659 families in the study population, of which 114 were from the pilot study DOS, 469 were recruited in the GeHA study, and 76 families came from the LLFS study, so that each family belonged uniquely to one of the three studies. For each of the three studies, a structured interview took place in the homes of the participants, where information on their siblings as well as on the offspring of the participants and the participants' siblings was gathered. Interviews were performed by five trained interviewers located in different parts of Denmark, thereby covering the entire country. It cannot be ruled out that unidentified offspring may have worse health profiles, but we expect that few offspring remain unidentified, as this means that their participating parent was unable or unwilling to provide name and birth date.

A total of 1511 siblings from the 659 families were interviewed, resulting in the identification of a total of 3972 siblings and 5379 offspring of siblings by providing names and birth dates of these siblings and offspring. To further ensure reliable family

\section{Recruitment flow chart}

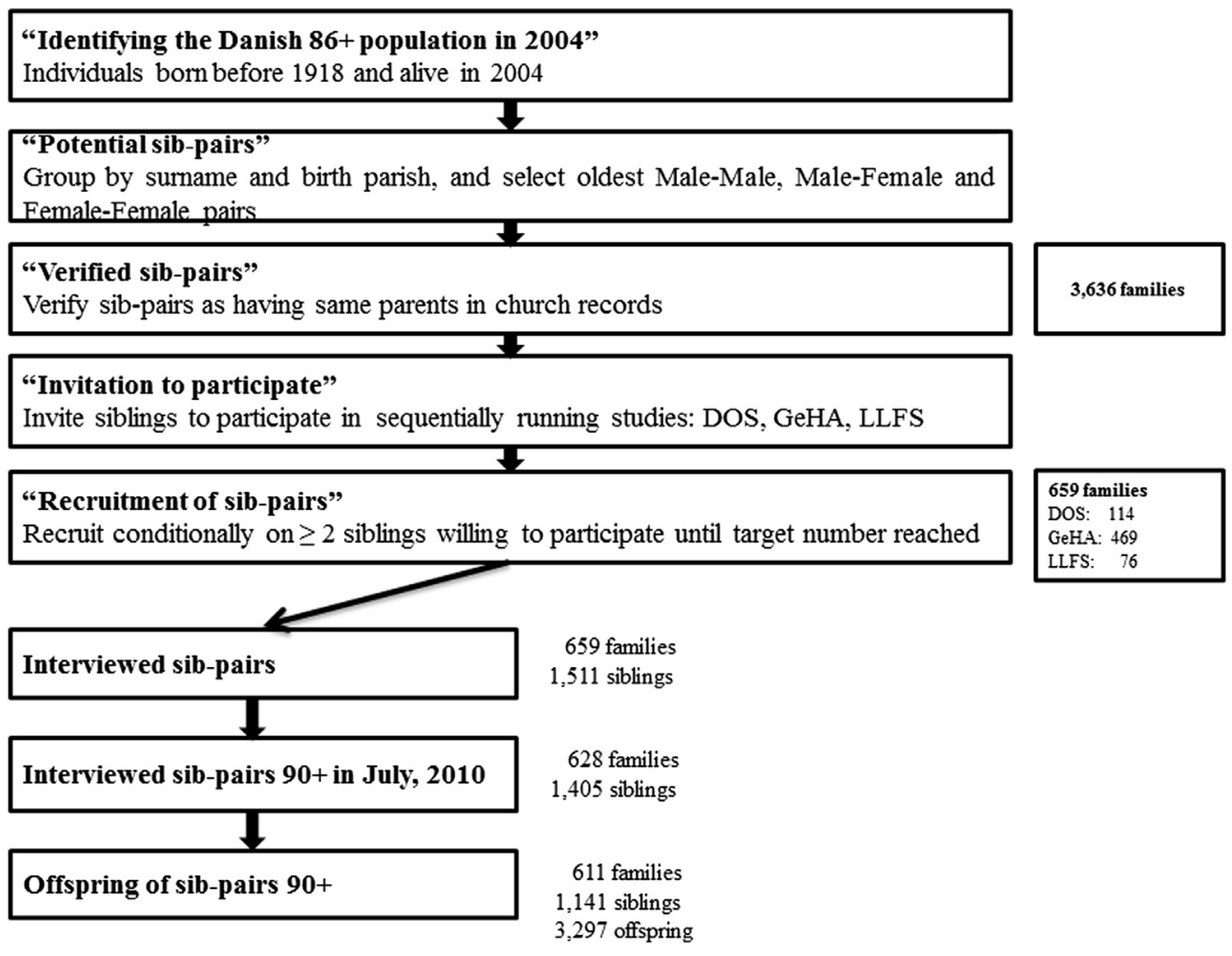

Fig. A1. Flow chart describing the sampling procedure leading to the recruitment of offspring of nonagenarian siblings in the study. 
Table A1

Descriptives of family characteristics for Danish families recruited in the three consecutive studies

\begin{tabular}{|c|c|c|c|c|c|c|}
\hline \multirow{2}{*}{$\frac{\text { Family characteristics }}{N}$} & \multicolumn{2}{|c|}{ DOS siblings } & \multicolumn{2}{|c|}{ GeHA siblings } & \multicolumn{2}{|c|}{ LLFS siblings } \\
\hline & 209 & & 969 & & 227 & \\
\hline \multicolumn{7}{|l|}{ Males } \\
\hline Number and percent & 102 & $48.8 \%$ & 321 & $33.1 \%$ & 82 & $36.1 \%$ \\
\hline \multicolumn{7}{|l|}{ Sib size } \\
\hline Median & 2 & & 2 & & 3 & \\
\hline Q1 and Q3 & 2 & 2 & 2 & 2 & 2 & 4 \\
\hline \multirow[t]{2}{*}{ Min and max } & 2 & 4 & 2 & 4 & 2 & 6 \\
\hline & \multicolumn{2}{|c|}{ DOS offspring } & \multicolumn{2}{|c|}{ GeHA offspring } & \multicolumn{2}{|c|}{ LLFS offspring } \\
\hline$N$ & 448 & & 2262 & & 557 & \\
\hline \multicolumn{7}{|l|}{ Males } \\
\hline Number and percent & 234 & $52.2 \%$ & 1120 & $49.5 \%$ & 287 & $51.5 \%$ \\
\hline \multicolumn{7}{|l|}{ Offspring per family } \\
\hline Median & 5 & & 5 & & 6 & \\
\hline Q1 and Q3 & 3 & 6 & 3 & 7 & 3 & 10 \\
\hline Min and $\max$ & 1 & 12 & 1 & 17 & 1 & 25 \\
\hline
\end{tabular}

Q1 = lower quartile; Q3 = upper quartile.

information and that the families in this study were strongly enriched for longevity, we restricted our study population to the offspring of those siblings who (1) participated in an interview in either DOS, GEHA, or LLFS; (2) survived to the age of 90 years or more before July 1, 2010; and (3) had at least another participating sibling surviving to the age of 90 years or more before July 1,2010 . This means that the population under study consisted of the offspring of those sets of siblings who survived to the age of 90 years or more and participated in an interview (in DOS, GEHA, or LLFS). So rather than using cohort and sex-specific cut points for classifying siblings as being long-lived, we used an operational criterion of both siblings having attained the age of 90 years regardless of sex and cohort. Although this means that some families, that is those from older birth cohorts and with one or both siblings being male, have been selected for a higher degree of longevity enrichment, all families are enriched for longevity. Names and dates for those alive in 1968 or later were later verified through DCRS, thereby providing the personal identification number and enabling the linkage of each individual to the various registries used in the study. A total of 1405 siblings from 628 families fulfilled this criterion: 99, 454, and 75 families in DOS, GeHA, and LLFS, respectively. Of the 1405 siblings, 264 had no offspring, so for the remaining 1141 siblings from 611 families, 3297 offspring were identified. Of these offspring, six had unknown vital status in the DCRS, further 17 had a status as emigrants at the end of study in 2009 but with an unknown date of emigration, and one with emigration status had emigrated before April 2, 1968; four offspring had died at an unknown date, and two had died before April 2, 1968. The remaining 3267 offspring from 610 families comprise our study population with 448 offspring from 97 DOS families, 2262 offspring from 438 GeHA families, and 557 offspring from 75 LLFS families (Fig. A1).

The similarities and differences between families recruited in the different studies are summarized in Tables A1-A3. In Table A1, we see that although the sex distribution among the siblings varied from about $50 \%$ males in the DOS study to about a third in the GeHA and LLFS studies, the sex distribution of the offspring was close to fifty-fifty for all three studies. This table also summarizes the tendency of larger sibships in families enrolled in the LLFS study, a tendency that is accentuated by the somewhat larger number of offspring in these families. Table A2 summarizes that the age distributions in the three studies were very similar. Similarity is also found when comparing cancer incidence in these three studies to the background Danish population stratified on sex, five-year age bands, and five-year calendar periods, as summarized in Table A3, especially when comparing the overall SIR between the three studies. The sex-specific SIRs vary moderately, but especially the DOS and LLFS studies have small samples within sex strata resulting in the somewhat wide CIs. Taking sampling variation into account, we find observed cancers to be about three-fourth of the expected number based on cancer rates in the Danish population.

Table A2

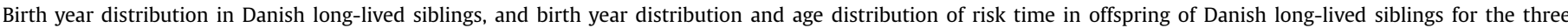
consecutive studies

\begin{tabular}{|c|c|c|c|c|c|c|c|c|c|}
\hline Birth year statistics & \multicolumn{3}{|c|}{ DOS siblings } & \multicolumn{3}{|c|}{ GeHA siblings } & \multicolumn{3}{|c|}{ LLFS siblings } \\
\hline$N$ & \multicolumn{2}{|c|}{209} & & \multicolumn{2}{|c|}{969} & & \multicolumn{2}{|c|}{227} & \\
\hline Families & \multicolumn{2}{|c|}{99} & & \multicolumn{2}{|c|}{454} & & \multicolumn{2}{|c|}{75} & \\
\hline \multicolumn{10}{|l|}{ Birth year } \\
\hline Median & \multicolumn{2}{|c|}{1911} & & \multicolumn{2}{|c|}{1912} & & \multicolumn{2}{|c|}{1913} & \\
\hline \multirow[t]{2}{*}{ Range } & \multicolumn{2}{|c|}{1897} & 1916 & \multicolumn{2}{|c|}{1901} & 1917 & \multicolumn{2}{|c|}{1902} & 1921 \\
\hline & \multicolumn{2}{|c|}{ DOS offspring } & & \multicolumn{2}{|c|}{ GeHA offspring } & & \multicolumn{2}{|c|}{ LLFS offspring } & \\
\hline$N$ & \multirow{2}{*}{\multicolumn{2}{|c|}{448}} & & \multirow{2}{*}{\multicolumn{2}{|c|}{2262}} & & \multirow{2}{*}{\multicolumn{2}{|c|}{557}} & \\
\hline \multicolumn{4}{|l|}{ Birth year } & & & & & & \\
\hline Median & \multirow{2}{*}{\multicolumn{2}{|c|}{$\begin{array}{l}1944 \\
1921\end{array}$}} & & \multirow{2}{*}{\multicolumn{2}{|c|}{$\begin{array}{l}1944 \\
1925\end{array}$}} & & \multirow{2}{*}{\multicolumn{2}{|c|}{$\begin{array}{l}1945 \\
1926\end{array}$}} & \\
\hline Range & & & 1969 & & & 1970 & & & 1969 \\
\hline \multirow[t]{2}{*}{ Age interval } & \multicolumn{2}{|l|}{ Time at risk } & Cancers & \multicolumn{2}{|l|}{ Time at risk } & Cancers & \multicolumn{2}{|l|}{ Time at risk } & Cancers \\
\hline & person-years & $\%$ & & person-years & $\%$ & & person-years & $\%$ & \\
\hline Age $0-30$ y & 3249.2 & $17.7 \%$ & 2 & $15,833.1$ & $17.4 \%$ & 3 & 4431.4 & $19.7 \%$ & 1 \\
\hline Age $30-50$ y & 8543.5 & $46.7 \%$ & 6 & $43,217.9$ & $47.6 \%$ & 52 & $10,639.1$ & $47.3 \%$ & 15 \\
\hline Age $50-60$ y & 3930.9 & $21.5 \%$ & 24 & $19,840.7$ & $21.8 \%$ & 92 & 4765.1 & $21.2 \%$ & 24 \\
\hline Age $60-70 \mathrm{y}$ & 2207.3 & $12.1 \%$ & 21 & $10,655.3$ & $11.7 \%$ & 120 & 2336.0 & $10.4 \%$ & 19 \\
\hline Age $70-80$ y & 369.1 & $2.0 \%$ & 9 & 1309.1 & $1.4 \%$ & 27 & 325.3 & $1.4 \%$ & 8 \\
\hline Age $>80 y$ & 13.0 & $0.1 \%$ & 0 & 20.5 & $0.0 \%$ & 0 & 9.3 & $0.0 \%$ & 0 \\
\hline Total & $18,313.1$ & & 62 & $90,876.6$ & & 294 & $22,506.3$ & & 67 \\
\hline Affected persons & & & 57 & & & 274 & & & 66 \\
\hline
\end{tabular}


Table A3

Cancer incidence in offspring of Danish long-lived siblings, from 1968 to 2009, stratified on study of enrollment

\begin{tabular}{llllccll}
\hline Study Gender & $\begin{array}{l}\text { No. of } \\
\text { families }\end{array}$ & $\begin{array}{l}\text { No. of } \\
\text { individuals }\end{array}$ & $\begin{array}{l}\text { Observed } \\
\text { no. of } \\
\text { cancers }\end{array}$ & $\begin{array}{l}\text { Expected } \\
\text { no. of } \\
\text { cancers }\end{array}$ & $\begin{array}{l}\text { SIR } \\
\text { (obs/exp) }\end{array}$ & 95\% CI \\
\hline DOS & Males & 91 & 234 & 25 & 42.4 & 0.59 & $0.39-0.89$ \\
& Females & 86 & 214 & 37 & 36.9 & 1.00 & $0.72-1.40$ \\
& All & 97 & 448 & 62 & 79.3 & 0.78 & $0.60-1.03$ \\
GeHA & Males & 398 & 1,120 & 116 & 172.4 & 0.67 & $0.56-0.81$ \\
& Females & 397 & 1,142 & 178 & 205.4 & 0.87 & $0.74-1.02$ \\
& All & 438 & 2,262 & 294 & 377.7 & 0.78 & $0.69-0.88$ \\
LLFS & Males & 66 & 287 & 34 & 43.0 & 0.79 & $0.56-1.12$ \\
& Females & 70 & 270 & 33 & 45.7 & 0.72 & $0.49-1.06$ \\
& All & 75 & 557 & 67 & 88.7 & 0.76 & $0.57-1.00$ \\
\hline
\end{tabular}

Exp $=$ expected number of cancers; obs = observed number of cancers.

\section{References}

[1] Pedersen CB. The Danish Civil Registration System. Scand J Public Health 2011;39(Suppl 7):22-5.

[2] Skytthe A, Valensin S, Jeune B, Cevenini E, Balard F, Beekman M, et al. Design, recruitment, logistics, and data management of the GEHA (Genetics of Healthy Ageing) project. Exp Gerontol 2011;46(11):934-45.

[3] Sebastiani P, Hadley EC, Province M, Christensen K, Rossi W, Perls TT, et al. A family longevity selection score: ranking sibships by their longevity, size, and availability for study. Am J Epidemiol 2009;170(12):1555-62. 